\title{
Particle size of aggregate and its influence upon the expansion caused by the alkali-silica reaction*
}

\author{
D. W. Hobbs and W. H. Gutteridge \\ Contribution by Alek Samarin \\ Ready Mixed Concrete Ltd, Australia, Central Research Laboratories
}

One of the most effective methods of inhibiting the expansion of reactive aggregate is by the addition of a sufficiently large quantity of pozzolana to concrete. The method is well publicized and documented, and even covered by ASTM Designation C441-69 (reapproved in 1975). "Standard test method for effectiveness of mineral admix tures of concrete due to the alkali-aggregate reaction".

Pozzolans produced by fine-grinding of potentially reactive opaline materials ${ }^{(1)}$ and even pozzolans with relatively high alkali contents ${ }^{(2)}$ have been reported to be quite effective inhibitors of alkaliaggregate reaction. Hence, one of the potential methods of prevention of alkali-aggregate reaction may be by means of pulverization of the portion of reactive aggregate in lieu of additions of pozzolana from external sources, when the latter are not economically available in a particular location.

Potential pozzolanicity of pulverized material can be evaluated either by the ASTM method mentioned

\section{Reply by the authors}

We thank Mr Samarin for his interest in our paper and agree that the addition of finely ground reactive material might be an effective method of reducing expansion due to the alkali-silica reaction. The amount of ground material required is dependent upon the alkali content of the cement and the in tended mix proportions of the concrete. We suggest above or by means of X-ray diffraction (XRD) analysis. For example, pulverized beer-bottle glass ${ }^{(3)}$ was found to be pozzolanic, as shown in Figure I (overleaf).

According to Celani et al. ${ }^{(4)}$, in mixes containing pozzolana no line at $9.80 \AA$ (which is normally associated with calcium silicate hydrate of high $\mathrm{CaO} / \mathrm{SiO}_{2}$ ratio) is present. Portlandite is characterized by the distinct lines at $4.90,2.628,1.927$ and $1.796 \AA$.

The differences between XRD read-out on a Portland cement matrix and a matrix containing pulverized glass do confirm the pozzolanic character of fine ground glass. In contrast, large particles of the same crushed glass exhibited typical alkali-aggregate reaction ${ }^{(3)}$. Utilization of pozzolanic properties of finely ground reactive materials may well be one of the practical aspects, related to the influence of particle size upon the expansion caused by the alkali-silica reaction.

that this pulverized material reacts rapidly with the water-soluble alkal is from the cement and that no deleterious expansion will occur when the watersoluble alkali level in the concrete is reduced to less than $2.5 \mathrm{~kg} / \mathrm{m}^{3(5)}$. We deduce from Diamond and Thaulow's data ${ }^{(6)}$ that the reactive material must be ground to less than $20 \mu \mathrm{m}$ for it to be effective.

\section{REFERENCES}

1. BENNETt, I. C. and vivian, H. E. Studies in cement-aggregate reaction. XXII: The effect of fine ground opaline material on mortar expansion. Australian Joumal of Applied Science. Vol. 6, No. 1. 1955. pp. 88-93.

* Pages 235-242 of MCR 109

2. KENNEDY, T. B. et al. Influence of alkali content of fy ash on effectiveness in preventing expansion of concrete. Vicksburg, U.S. Army Engineer Waterways Experiment Station, June 1963. Technical Report No. 6-627. 


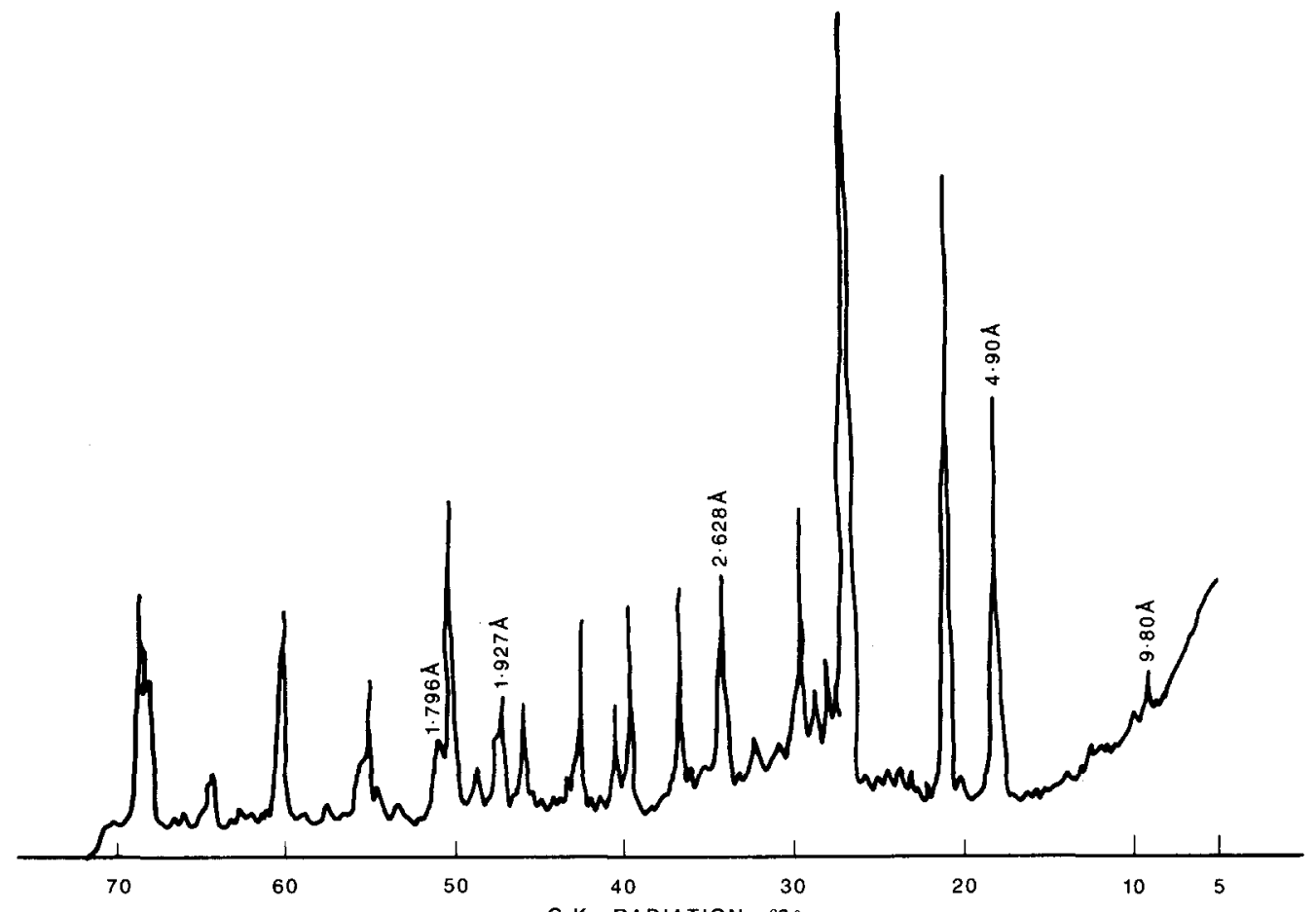

(a) Portland cement matrix

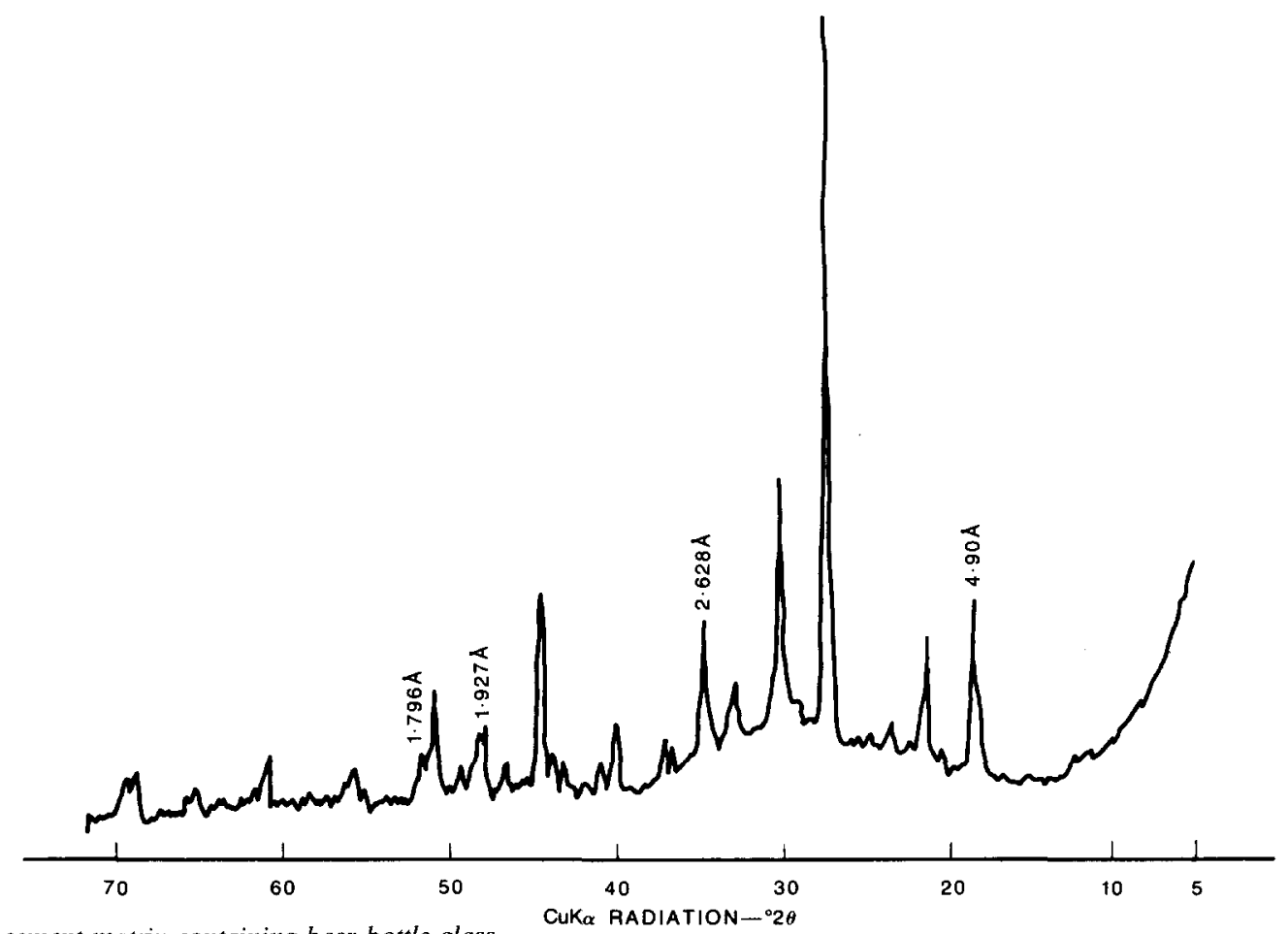

(b) Portland cement matrix containing beer-bottle glass Figure I: $\mathrm{CuK \alpha}$ radiation results.

3. SAMARIN, A. Use of fine crushed bottle glass sand and partial cement replacement in concrete. Proceedings of the International Conference on Materials of Construction for Developing Countries, August 22-24, 1978, Bangkok, Thailand. pp. 369-392.

4. CELANI, A., MOGgI, P. A. and RIO, A. The different action mechanism of pozzolanic materials and slags in the hydraulic binders. Proceedings of the Fifth International Symposium on the Chemistry of Cement, Tokyo, 1968. Part IV: Admixtures and special cements. Tokyo, The Cement Association of Japan, 1969. p. 145.
5. новвS, D. w. Influence of mix proportions and cement alkali content upon expansion due to the alkali-silica reaction. Wexham Springs, Cement and Concrete Association, June 1980. pp. 31. Technical Report 534 (Publication 42.534).

6. Diamond, s. and thaulow, N. A study of expansion due to alkali-silica reaction as conditioned by grain size of the reactive aggregate. Cement and Concrete Research. Vol. 4, No. 4. July 1974. pp. 591-607. 